\section{Matching in a concurrent FI FI schedule*}

\author{
CHARLES P. SHIMP \\ University of Utah, Salt Lake City, Utah 84112
}

Three pigeons responded in a two-key concurrent fixed-interval fixedinterval reinforcement schedule. The schedule had two parts: one fixed-interval $30-\mathrm{sec}$ schedule and a Bernoulli trials generator that probabilistically assigned a reinforcement to the left or right key, independently of the preceding assignment. The relative frequency of responding on a key approximately equaled the probability of reinforcement on that key.

In a two-key concurrent variable-interval variable-interval (Conc VI VI) schedule of reinforcement, a pigeon produces an approximate equality between the relative frequency of responding on a key and the relative frequency of reinforcement on that key (Herrnstein, 1970). One method of programming such a reinforcement schedule has two parts: one VI tape and a Bernoulli trials generator that allocates a reinforcement assigned by the VI tape to the left or right key with some fixed probability that is independent of the preceding allocation. (For an example of such a Conc VI VI, see Shimp, 1969, Experiment I.) Now, the VI tape could be replaced by any other kind of schedule. Specifically, it could be replaced by a fixed-interval (FI) tape, and it then could be asked if a bird would still match its relative frequency of responding on a key to the relative frequency of reinforcement on that key. The change from a VI to a FI tape would change

* This research was supported by NIMH Grant No. 16928 to the author, who would like to thank Georgianne Kise for running the Ss.

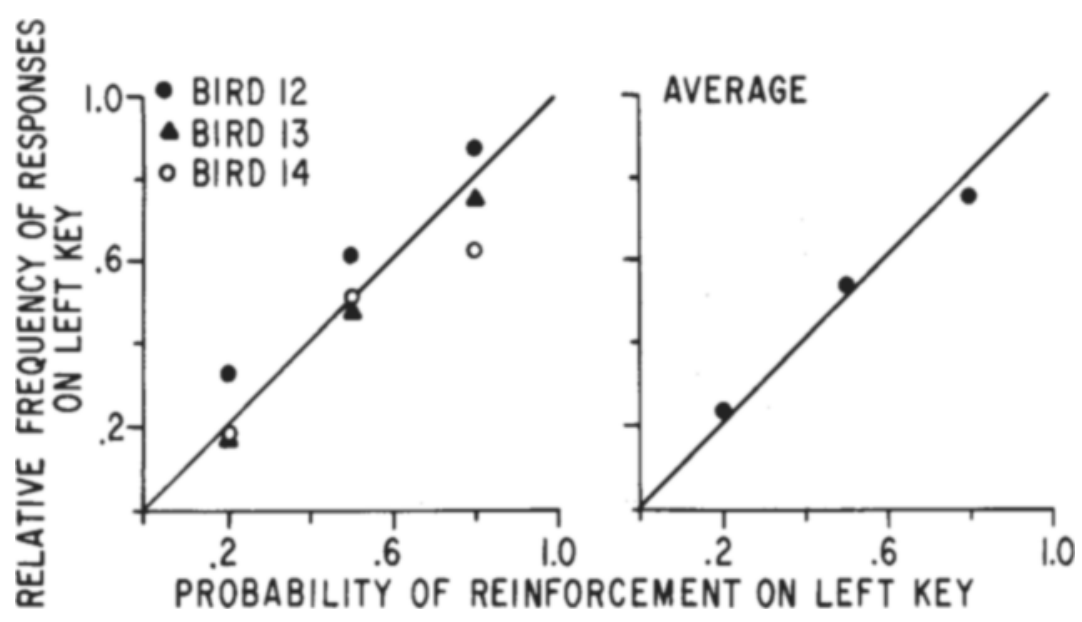

Fig. 1. The relative frequency of responding on the left key as a function of the probability of reinforcement on that key in a concurrent fixed-interval fixed-interval schedule.

standard three-key Lehigh Valley Electronics pigeon chamber. Only the left and right keys were used here. Reinforcement contingencies were programmed by commercial relay apparatus and an isolation transformer provided flicker-free illumination of the translucent pecking key. White noise masked extraneous sounds. PROCEDURE

The reinforcement schedule consisted of two separate parts: a FI 30 -sec programmer and a Bernoulli trials generator. The FI $30-\mathrm{sec}$ programmer started to run at the end of a reinforcement (or, in the case of the first interval in a session, at the beginning of the session). By the time the $30 \mathrm{sec}$ had timed out, the Bernoulli trials generator had assigned the coming reinforcement to the left or to the right key. There was an unlimited hold on each programmed reinforcement in the sense that, once programmed on a key, a reinforcement remained programmed on that key until it was collected.

Interresponse times shorter than $1 \mathrm{sec}$ were not reinforced. That is, after a reinforcement was programmed by the FI schedule and the Bernoulli trials generator, the reinforcement was delivered for the first response to terminate an IRT longer than 1 sec. This contingency was imposed in an attempt to stabilize response topography. Also, this contingency provided a 1-sec change-over delay.

Each session was $45 \mathrm{~min}$ in duration. Reinforcement consisted of 2 sec of access to mixed grain. During reinforcement the houselight and the key light were darkened.

After an initial shaping procedure, each bird was given 11,14 , and 9 days of training, with the probability of reinforcement on the left key equal to $0.5,0.2$, and 0.8 , respectively.

$$
\text { RESULTS }
$$

The left panel of Fig. 1 shows that the relative frequency of responding on the left key approximately equaled the relative frequency of reinforcement on that key for each of the three birds. (Each symbol in the figure represents the average for that bird over the last 5 days of a condition.) Pigeon 12 had a slight preference for the left key and Pigeon 13 had a very slight preference for the right key. The right panel in Fig. 1 shows that the averages of the three Ss' relative frequencies of responding closely matched the corresponding reinforcement probabilities.

\section{DISCUSSION}

One way to program a Conc VI VI schedule has two parts: a single VI schedule and a Bernoulli trials generator. In the present experiment the VI schedule was changed to a FI schedule. In the resulting Conc FI FI the relative frequency of pecking a key approximately equaled the probability of reinforcement on that key, just as in Conc VI VI. Thus, the distribution of interreinforcement intervals that will result in matching behavior is 
broader than has been previously demonstrated. While the distribution of interreinforcement intervals is different in Conc VI VI and Conc FI FI, the schedules are similar in that in both schedules the probability of reinforcement on a key increases as a bird spends time responding on the other key. However, there are quantitative differences in the way in which this increase comes about in Conc VI VI and Cone FI FI.

The major outcome of the present experiment is the suggestion that matching may be obtained in a broader class of schedules than Conc VI VI. Perhaps ratio schedules, etc., also could be used in place of the VI schedule to generate matching with the present method of programming concurrent schedules.

\section{REFERENCES}

HERRNSTEIN, R. J. On the law of effect. Journal of the Experimental Analysis of Behavior, 1970, 13, 243-266.

SHIMP, C. P. The relative frequency of an interresponse time equals its relative harmonic length. Journal of the Experimental Analysis of Behavior, 1969, $12,403-411$.

\section{A new coordination test of visual-motor deprived visually experienced cats*}

\author{
STEPHEN E. FISH and JOHN S. ROBINSON \\ Brain-Behavior Research Center, Eldridge, Calif. 95431
}

Cats with extensive binocular visual experience but with only monocular visual-motor experience were found to have visual-motor deficits in both deprived and experienced eyes when tested on a new apparatus requiring smooth negotiation of a series of barriers.
Currently used methods for measuring visual-motor behavior in immature. deprived, or lesioned animals are still relatively primitive. Simple observation of obstacle avoidance during free movement and the relatively crude visual placing response test are frequently used. Recently Hein \& Held (1967) described a version of the latter modified to measure behavior requiring more precise visual guidance.

The barrier apparatus described here allows one to make qualitative observations and objective measurements of the complex movements required in the cat's visually guided locomotion among obstacles. The task can be made sensitive enough to detect differences between a normal S's eyes. The apparatus will be described and its use illustrated by showing

* This work was supported in part by Grants WH 08832 and HD 05317 from the National Institutes of Health, L.S. Public Health Service. providing $\mathrm{Ss}$ with visual experience while preventing them from using it in getting about.

\section{BARRIER APPARATUS FOR MEASLRING VISUAL-MOTOR COORDINATION}

The five 18-in.-high barriers in the apparatus illustrated in Fig. 1 are 18 in. apart and have 14 slats. A racking frame which rests on side pieces can be pushed or pulled from either end to set all the slats so that they lean one way or the other. The slat guide device is shown in the insert. The large nail "lateral restraining pin" in the top of the slat and the "brad pivot" in the bottom allow the slat to rock back and forth but prevent sideways movement. The "support bar" limits the fall of the slats: Tipped forward the slats come to rest against the bar: tipped how it was adapted to study the effects of

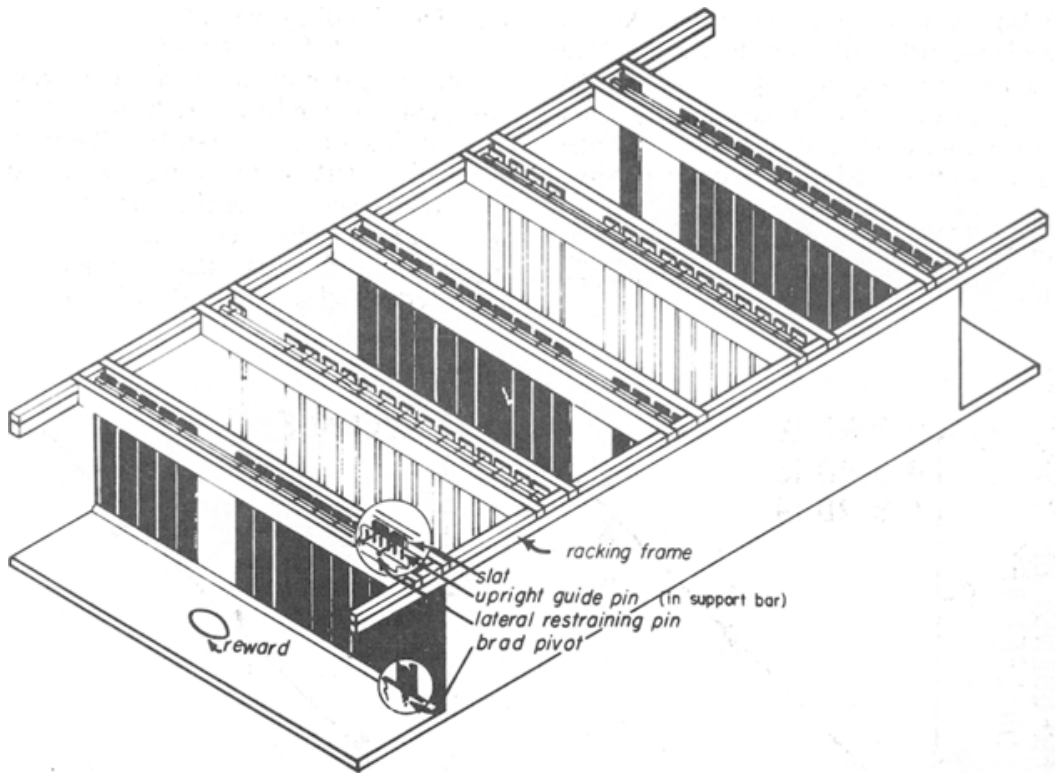

Fig. 1. Barrier apparatus for testing visual-motor coordination. The $\mathrm{S}$ must use visual cues in finding the most direct path to the reward and in adjusting movements so that passage through the openings is smooth. 